\title{
Piecewise Model and Parameter Obtainment of Governor Actuator in Turbine
}

\author{
Jie Zhao, Li Wang, Dichen Liu, and Jun Wang \\ School of Electrical Engineering, Wuhan University, Wuhan 430072, China \\ Correspondence should be addressed to Jie Zhao; jiez_whu@whu.edu.cn
}

Received 13 December 2014; Revised 10 March 2015; Accepted 10 April 2015

Academic Editor: Georgios Sirakoulis

Copyright (C) 2015 Jie Zhao et al. This is an open access article distributed under the Creative Commons Attribution License, which permits unrestricted use, distribution, and reproduction in any medium, provided the original work is properly cited.

The governor actuators in some heat-engine plants have nonlinear valves. This nonlinearity of valves may lead to the inaccuracy of the opening and closing time constants calculated based on the whole segment fully open and fully close experimental test curves of the valve. An improved mathematical model of the turbine governor actuator is proposed to reflect the nonlinearity of the valve, in which the main and auxiliary piecewise opening and closing time constants instead of the fixed oil motive opening and closing time constants are adopted to describe the characteristics of the actuator. The main opening and closing time constants are obtained from the linear segments of the whole fully open and close curves. The parameters of proportional integral derivative (PID) controller are identified based on the small disturbance experimental tests of the valve. Then the auxiliary opening and closing time constants and the piecewise opening and closing valve points are determined by the fully open/close experimental tests. Several testing functions are selected to compare genetic algorithm and particle swarm optimization algorithm (GA-PSO) with other basic intelligence algorithms. The effectiveness of the piecewise linear model and its parameters are validated by practical power plant case studies.

\section{Introduction}

Power system analysis is essential for the system security and stability. For medium and long term stability analysis, such as the frequency control, the mathematical model of prime mover and its governor and the accuracy of the parameters are critical [1-4]. After the blackout accidents occurred in the Western United States in 1996, the World Electronic Circuits Council (WECC) in 2001 conducted two large units tripped disturbance tests in the Western United States grid, and the study found that the frequency response of original speed governor model did not match with the measured response process; thus a new thermal governor system model was established to improve the simulation accuracy [5]. To identify parameters and simulate the characteristics of the speed regulation system based on experimental test data is a fundamental work for the power system. Therefore, the study of prime mover and its governor simulation model and parameters identification for the power system is of importance to the theoretical and practical value.

Studies on parameter identification methods of steam turbine governor for different simulation cycles can be found in [6-11]. The fixed oil motive opening and closing time constants are adopted in the existing literatures and power system simulation software settings [9-12], but they are difficult to be applied to the nonlinear characteristics of some thermal power plant actuator valve's fully open or close test. As for the nonlinear valve of hydroturbine, certain existing literature uses several sets of proportional integral derivative (PID) parameters to meet the different operating conditions [13]. However, PID parameters tuning based on intelligent algorithm is relatively complex, so a compromised parameter identification method under different working conditions is required to avoid the difficulty caused by the large number of PID parameters. For parameter identification methods, the classical methods [14] are only applicable to linear system whereas the intelligent algorithms [13,15-19] are widely used due to robustness in presence of the input disturbance signals, such as input noises. Nevertheless, the measured data can be easily polluted by the noise, and the parameters need to be identified in time.

For different plants, the speed limit value of the oil motive movement is different through valve fully open and fully 


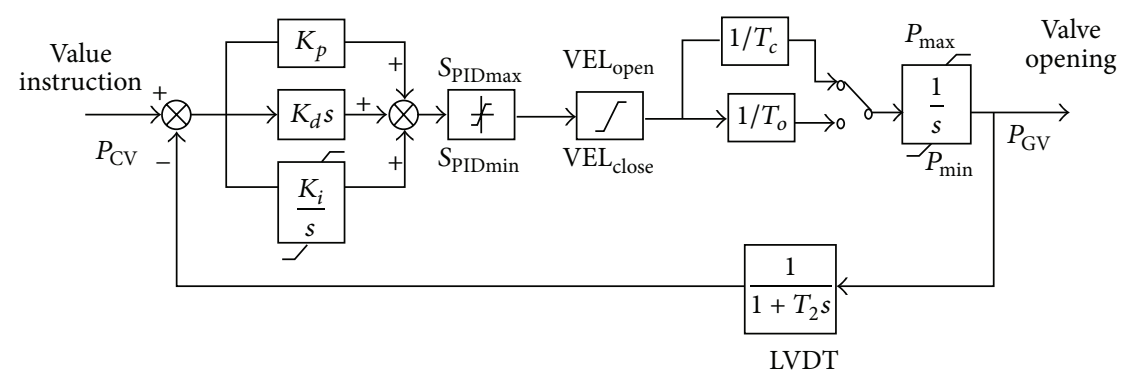

FIgURE 1: Servo and actuator system model.

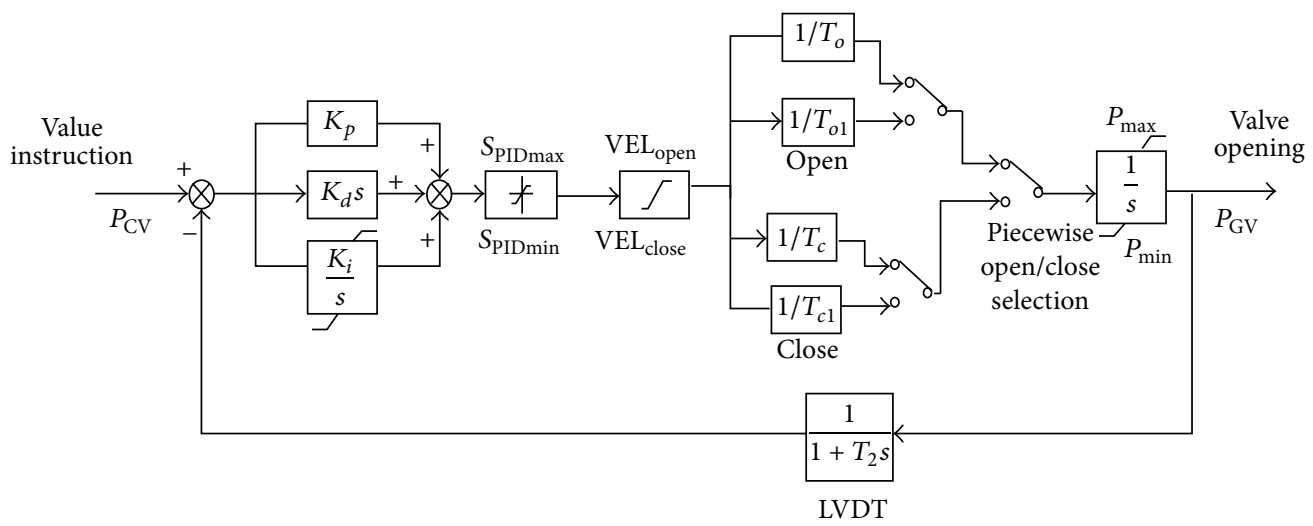

FIgURE 2: Improved model of servo and actuator system.

close test, so that to get the speed limit value is the key to simulate the characteristics of governor actuator with high precision, since speed limit is related to the oil motive opening and closing time constants. For some thermal power plants, the valve is nonlinear. As a result, piecewise speed limit is adopted, not only the maximum and minimum speed limit. The governor actuator piecewise linear model is established based on the movement principle of the oil motive.

The paper is organized as follows. In Section 2, a governor actuator piecewise linear model is established (hereinafter referred to as the improved model of servo and actuator system) using piecewise opening and closing time constants, including the main opening and closing time constants and the auxiliary opening and closing time constants. The effectiveness of genetic algorithm-particle swarm optimization (GA-PSO) algorithm is compared with other basic intelligence algorithms, through selection of multiple test functions in Section 3. Aimed at the nonlinear characteristics of actuator valve, the calculation method of main opening and closing time constants and their influence on PI parameter identification are discussed in Section 4 and the results and discussion are presented in this section as well. Conclusions are finally drawn in Section 5.

\section{Governor Actuator Mathematical Model and Parameter Identification Steps}

2.1. Governor Actuator Mathematical Model. Electrohydraulic servo and actuator are essential, one of the most important factors influencing the dynamic characteristics of the speed control system and the ability of primary frequency speed control $[20,21]$. The actuator amplifies and converts control signal from the regulator to the opening of the valve, to control steam flow into the turbine. The mathematical model is shown in Figure 1 , where $K_{p}, K_{i}$, and $K_{d}$ are the proportional, integral, and derivative multiple coefficients of the integrated amplifier module, respectively, which is commonly proportional or proportional plus integral part. $S_{\text {PIDmax }}$ and $S_{\text {PIDmin }}$ are the upper and low limits of the integrated amplifier module, respectively. $\mathrm{VEL}_{\text {open }}$ and $\mathrm{VEL}_{\text {close }}$ denote the rapid opening and rapid closing coefficient, respectively. $T_{o}$ and $T_{c}$ denote the oil motive opening and closing time constants, respectively. $P_{\max }$ and $P_{\min }$ are the maximum and minimum valve opening value, respectively. $T_{2}$ is the oil motive stroke feedback link time constant, usually taken as 0.02 seconds.

When the valve moves sharply, the servo valve output reaches its limit position, and the oil motive has the maximum opening or closing regulating speed. The output value demonstrates linearity. However, nonlinear valve cases exist and the model in Figure 1 is no longer applicable. Thus an improved model of servo and actuator system is shown in Figure 2, where $T_{o 1}$ and $T_{c 1}$ also are the opening and closing time constants, respectively, and for the distinction, $T_{o}$ and $T_{c}$ are defined as the main opening and closing time constants, respectively. $T_{o 1}$ and $T_{c 1}$ are defined as the auxiliary opening and closing time constants, respectively. The piecewise opening and closing valve points are determined according to the actual condition. 


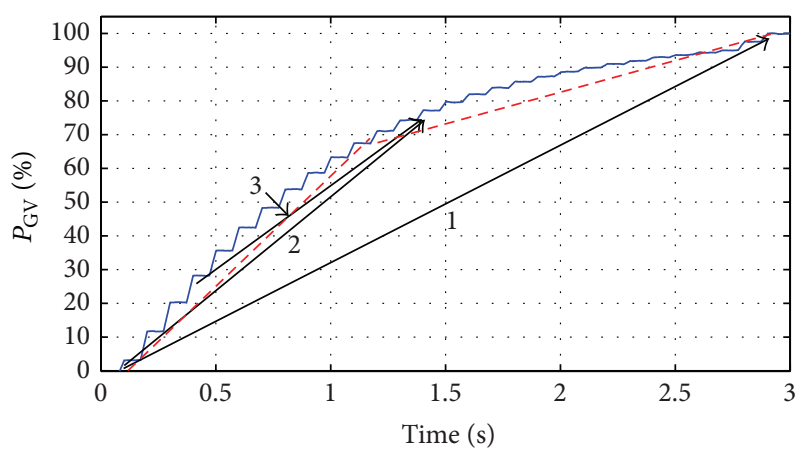

(1) The whole

(2) The front

(3) The middle

FIgURE 3: Opening time constant calculation diagram.

As the model shown in Figure 2, the oil motive operates by applying the main opening and closing time constant when the valve responds to a small disturbance; under big disturbances, the oil motive soon reaches its maximum adjusting speed. In other words, oil motive firstly operates linearly by the main opening and closing time constant. When it is close to the steady state, it acts with the auxiliary opening and closing time constant. So the model can be applied to both linear and nonlinear valves. Parameters that need to be identified in this model are the main and auxiliary piecewise opening and closing time constants of the oil motive, PI parameters, namely, $K_{p}$ and $K_{i}$.

2.2. Parameter Identification Steps. The current existing method to obtain the oil motive opening and closing time constants is based on the fully open or close test curves of the actuator [22]. When the valve operates nonlinearly, taking the fully open test as an example, the diagram using different segmented curves to obtain the oil motive opening time constant is shown in Figure 3.

(a) The whole segment: the valve moves from fully closed to fully open.

(b) The front segment: the valve moves from fully closed to about 75 percent opening.

(c) The middle segment: the valve moves from about 25 percent opening to 75 percent opening.

The blue curve in Figure 3 is the measured actuator fully open curve and the dotted line uses the piecewise opening time constants. If the main opening time constant is obtained from the front segment curve data of fully open test, the expression is shown as

$$
T_{o}=\frac{\left(\lambda_{1} P_{\max }-P_{\min }\right)}{\Delta t_{1}} .
$$

If the main closing time constant is obtained from the front segment curve data of fully close test, the calculation method is

$$
T_{c}=\frac{\left(P_{\max }-\lambda_{2} P_{\max }\right)}{\Delta t_{2}},
$$

where $\lambda_{1}$ and $\lambda_{2}$ are constant coefficients. The whole or middle segment curve of the fully open/close test can also be applied to calculate $T_{o}$ and $T_{c}$, and the expressions are similar to (1)-(2).

Assuming that the piecewise opening and closing valve points are $Y_{o}$ and $Y_{c}, T_{o 1}$ and $T_{c 1}$ are generally defined as

$$
\begin{aligned}
& T_{o 1}=\frac{\left(P_{\max }-Y_{o}\right)}{\Delta t_{3}}, \\
& T_{c 1}=\frac{\left(Y_{c}-P_{\min }\right)}{\Delta t_{4}},
\end{aligned}
$$

where $\Delta t_{1}, \Delta t_{2}, \Delta t_{3}$, and $\Delta t_{4}$ in (1) to (3) are the corresponding time of the curves in the valve opening change process.

The procedure to obtain parameters of the modified actuator model is described as follows.

Step 1. Process the selected input valve instruction and the output valve opening data with the method of wavelet denoising.

Step 2. Calculate the main opening and closing time constants through the linear segment of the fully open or close test curve.

Step 3. Identify $K_{p}$ and $K_{i}$ using small disturbance experimental tests data of the valve.

Step 4. Determine the piecewise opening and closing valve points and the auxiliary opening and closing time constants through fully open or close test curve.

Step 5. Check actuator parameters.

The actuator parameter identification process of servo and actuator is shown in Figure 4.

\section{The Parameter Identification Method Based on GA and PSO Algorithm}

3.1. The Parameter Identification Method. An improved particle swarm optimization (IPSO) algorithm and GA-PSO algorithm are presented to identify parameters. Particle swarm optimization [17-19] is a kind of bionic algorithm to solve optimization problems. The location and speed of particle should be constantly updated. The concept of inertia weight is introduced to revise the speed update equation to improve search in the global scope. To further enhance the search ability, the learning factors $c_{1}$ and $c_{2}$ are linearly changed and the convergence factor is introduced:

$$
\lambda=\frac{2}{\left|2-c_{1}-c_{2}-\sqrt{\left(c_{1}+c_{2}\right)^{2}-4\left(c_{1}+c_{2}\right)}\right|} .
$$




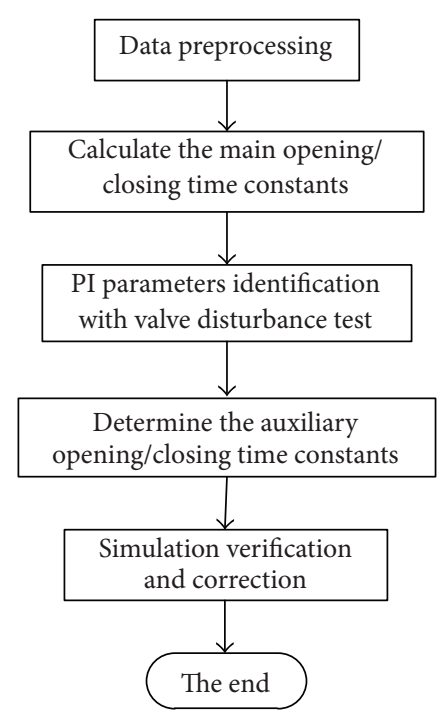

Figure 4: The parameter identification process of servo and actuator.

Then the location update equation is

$$
x_{i D}^{k+1}=x_{i D}^{k}+\lambda \cdot v_{i D}^{k+1} .
$$

To improve the performance of the initial solution, chaos method is used to generate initial particle population. The two-dimensional chaotic map is

$$
\begin{aligned}
& x_{n+1}=\left(x_{n}+y_{n}\right) \bmod 1, \\
& y_{n+1}=\left(x_{n}+2 y_{n}\right) \bmod 1 .
\end{aligned}
$$

Genetic algorithm (GA) [9] is also a kind of optimization method simulating natural biological evolution mechanism applied to many optimization problems. However, it has its limitations such as low efficiency and premature convergence. So a combined GA-PSO algorithm is used to improve optimization performance, and the algorithm process is shown in Figure 5.

The algorithm process of GA-PSO is divided into four parts: Part (1) for particle initialization; Part (2) for genetic algorithm initialization; Part (3) for extremum comparison; Part (4) for the particle position and speed update. Individual fitness value is determined by objective function and the following criterion function is used as fitness function

$$
f=\frac{\left(\sum_{i=1}^{N}\left(y(i)-y_{0}(i)\right)^{2}\right)}{N},
$$

where $N$ is the number of sampling points, $y(i)$ is the $i$ th simulation output value, and $y_{0}(i)$ is the $i$ th measured output value.

3.2. The Characteristic of Different Algorithms. The test functions of Griewank, Ackley, Schwefel, Shubert, and Schaffer $[23,24]$ are used to compare the optimizing performance of four algorithms (i.e., the basic PSO algorithm, IPSO

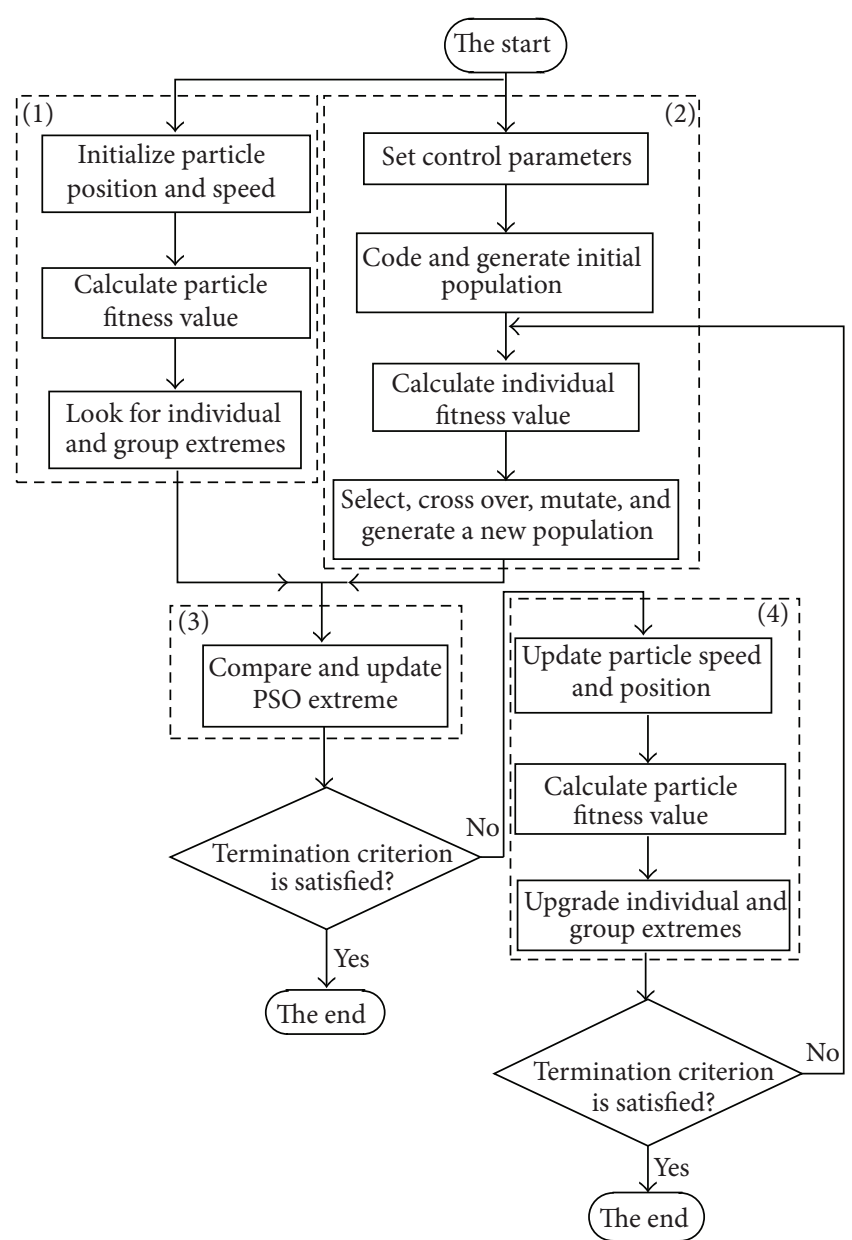

Figure 5: The algorithm process of GA-PSO.

algorithm, GA algorithm, and GA-PSO algorithm). The five test functions are named as $f_{1}$ to $f_{5}$, respectively.

For each test function, the algebra of four algorithms is 70 , and the maximum iteration step is 100 . For the functions with the extreme point of zero, the tolerance of error is set within $10^{-10}$, and the optimization of four algorithms is tested for 50 times. For each algorithm, the optimal value obtained by per optimization program running has little difference. The average runtime on optimization program costs, average optimal value, and standard deviation of four algorithms are shown in Table 1.

In Table 1, the average optimal value is displayed instead of the best and the worst optimal values of four algorithms. The results show that GA algorithm performs better for certain functions (e.g., $f_{3}$, namely, the Schwefel function) but the running time is longer. GA-PSO performs best overall with shorter running time.

Take the Schaffer function as an example to give evolving optimization curve. Under the condition of given precision, the fitness value curves of the four identification algorithms are shown in Figure 6.

The vertical axis in Figure 6 is the logarithm of fitness value. It shows that IPSO algorithm and GA-PSO algorithm can obtain higher accuracy with less algebra. 
TABLE 1: The average running time, average optimal value, and standard deviation of the four algorithms.

\begin{tabular}{|c|c|c|c|c|c|c|}
\hline & Function name & PSO & IPSO & GA & GA-PSO & Theory extreme \\
\hline \multirow{3}{*}{$f_{1}$} & Average runtime (s) & 0.115 & 0.092 & 0.453 & 0.199 & \multirow{3}{*}{0} \\
\hline & Average optimal value & 0.0049 & 0.0040 & 0.0125 & 0.0019 & \\
\hline & Standard deviation & 0.0071 & 0.0066 & 0.0188 & 0.0039 & \\
\hline \multirow{3}{*}{$f_{2}$} & Average runtime (s) & 0.166 & 0.115 & 0.501 & 0.230 & \multirow{3}{*}{0} \\
\hline & Average optimal value & $7.38 e-7$ & $6.04 e-11$ & 0.162 & $5.85 e-11$ & \\
\hline & Standard deviation & $1.07 e-6$ & $6.49 e-11$ & 0.5932 & $6.19 e-11$ & \\
\hline \multirow{3}{*}{$f_{3}$} & Runtime (s) & 0.164 & 0.170 & 0.487 & 0.336 & \multirow{3}{*}{-837.9} \\
\hline & Average optimal value & -822.55 & -814.28 & -837.96 & -834.41 & \\
\hline & Standard deviation & 42.70 & 55.55 & 0 & 20.51 & \\
\hline \multirow{3}{*}{$f_{4}$} & Average runtime (s) & 0.114 & 0.122 & 0.508 & 0.318 & \multirow{3}{*}{-186.7} \\
\hline & Average optimal value & -180.28 & -183.46 & -181.50 & -184.48 & \\
\hline & Standard deviation & 11.43 & 7.99 & 10.85 & 3.84 & \\
\hline \multirow{3}{*}{$f_{5}$} & Average runtime (s) & 0.156 & 0.122 & 0.465 & 0.241 & \multirow{3}{*}{0} \\
\hline & Average optimal value & 0.006 & 0.004 & 0.016 & 0.002 & \\
\hline & Standard deviation & 0.007 & 0.006 & 0.034 & 0.004 & \\
\hline
\end{tabular}

$6.49 e-11$ is equal to $6.49 \times 10^{-11}$.

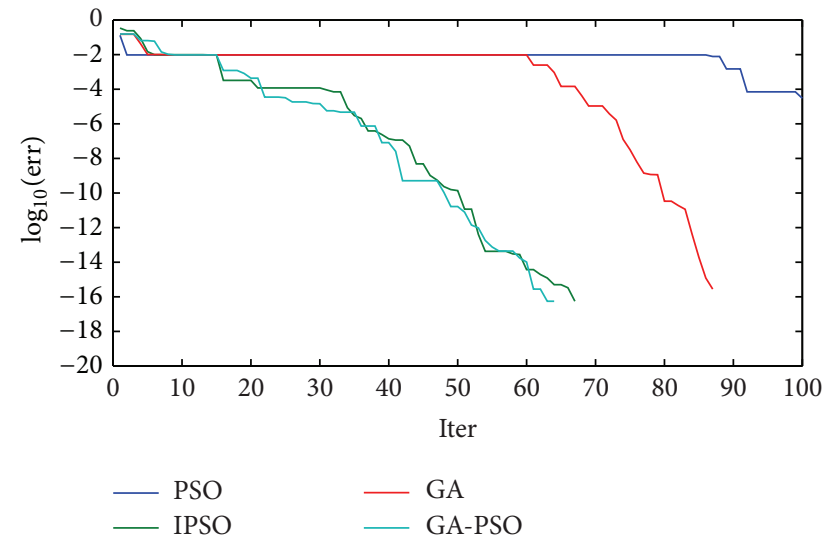

FIgURE 6: Curves comparison of fitness value.

By comparing several algorithms of five test function optimization results, the optimizing performance of these algorithms ranks from good to bad as follows: GA-PSO algorithm, IPSO algorithm, GA algorithm, and the basic PSO algorithm.

\section{Results and Discussion}

GA-PSO algorithm which has better parameters identification stability is used to identify the parameters of two different turbine governor actuators with linear and nonlinear characteristics, respectively, and the governor actuator piecewise linear model is verified. Two thermal power plants (i.e., Xiaolongtan power plant and Qujing power plant) with reheat steam turbine in Yunnan province of West China are adopted to test the improved model. The rated power of these two power plants is $300 \mathrm{MW}$. With the field static tests of turbine, actuator fully open or close wave record can be got,

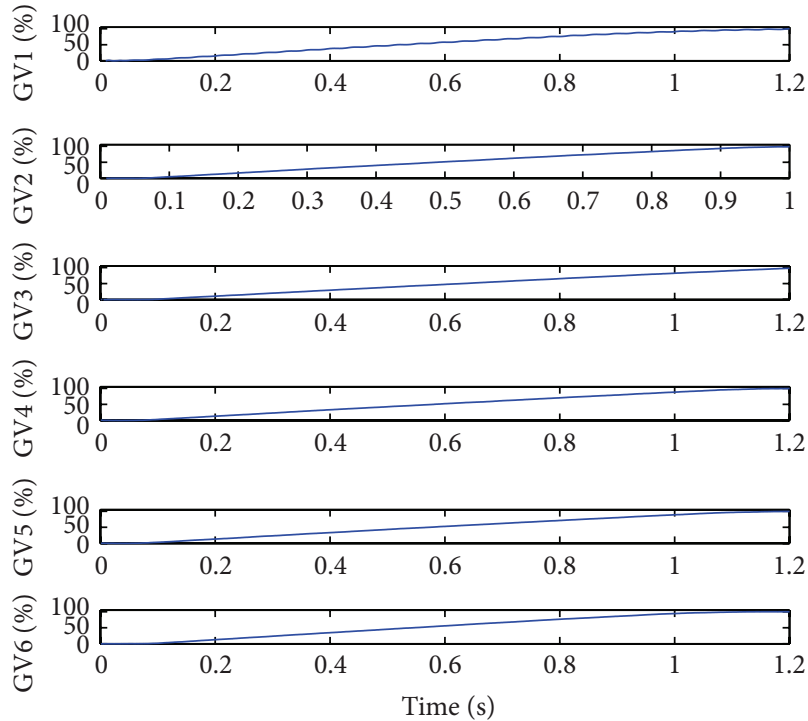

FIGURE 7: Servo and actuator fully open wave record of Xiaolongtan power plant.

as well as the input valve instruction and output valve opening data under small disturbance experimental tests of the valve.

4.1. The Verification of Piecewise Model. Xiaolongtan power plant with linear valve is studied to verify the improved servo and actuator system model. Fully open wave record of Xiaolongtan power plant is shown in Figure 7.

The valve fully open curve is approximately linear in Figure 7, as well as the fully close test curve. After analyzing each valve movement speed from the fully open and close tests, the valves with similar movement speed are selected. As a result, the main opening and closing time constants are $T_{o}=1.02$ seconds and $T_{c}=1.45$ seconds, and the piecewise 


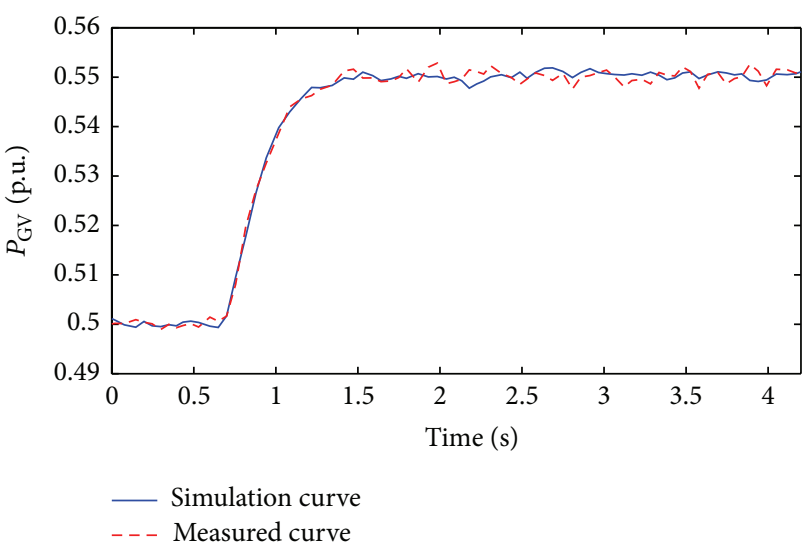

(a)

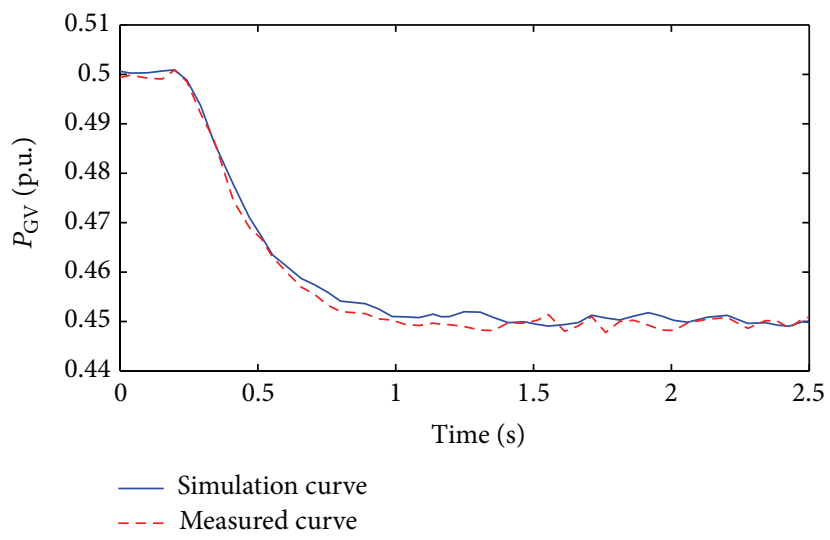

(b)

FIGURE 8: Valve opening simulation compared with the measured curve.

opening and closing valve points are approximate to be 0 . Therefore the auxiliary opening and closing time constants are set as $T_{o 1}=1.02$ seconds and $T_{c 1}=1.45$ seconds.

Take the average valve opening value of the six valve (i.e., GV1 to GV6) curves as the simulation compared valve opening value. The identification results by GA-PSO algorithm are $K_{p}=15.167, K_{i}=0$ under small disturbance experimental tests with valve opening ranging from $50 \%$ to $55 \%$ and valve opening ranging from $50 \%$ to $45 \%$. The valve opening simulation compared with the measured data is shown in Figure 8.

Figure 8 shows that the results identified by GA-PSO algorithm coincide with the measured data. For Xiaolongtan power plant, since the piecewise opening and closing valve points are set to 0 , the simulation results of the improved servo and actuator system model (see Figure 2) are similar to the servo and actuator system model in Figure 1.

\subsection{The Influence of Different Calculated Main Opening Time} Constants on PI Parameter Identification. Qujing power plant with nonlinear valve is also studied to verify the improved servo and actuator system model. The actuator fully open wave record of Qujing power plant is shown in Figure 9.

It can be seen from Figure 9 that the former period of fully open test curve is approximately linear, but it turns flat when being close to steady-state value. The fully closed test curve presents similar trend. Given $\lambda_{1}=0.7, \lambda_{2}=0.3$ in (1) to (2), the front, the middle, and the whole segment curve data of valve fully open test are selected to calculate the main opening time constant. Similarly, the main closing time constant is obtained. The results of different methods (see Figure 3) calculating the main opening and closing time constants are shown in Table 2.

Table 2 shows that since the fully open test curve is nonlinear, the main opening and closing time constant calculation results are different when using different curve data.

The valve opening data ranging from $50 \%$ to $55 \%$ under small disturbance is selected to discuss the influence of different main opening and closing time constant calculation results on PI parameter identification. The identified PI parameters using GA-PSO algorithm are shown in Table 3.
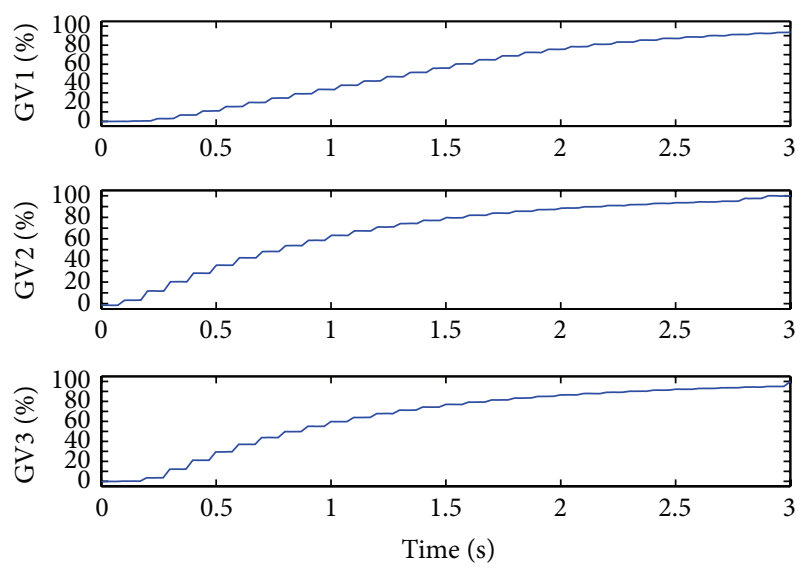

FIGURE 9: Servo and actuator full open recorded diagram of Qujing power plant.

TABLE 2: Main opening and closing time constant calculation results.

\begin{tabular}{lccc}
\hline Calculated & $\begin{array}{c}\text { The whole } \\
\text { segment }\end{array}$ & $\begin{array}{c}\text { The front } \\
\text { segment }\end{array}$ & $\begin{array}{c}\text { The middle } \\
\text { segment }\end{array}$ \\
\hline$T_{o}$ & 2.54 & 1.89 & 2.14 \\
$T_{c}$ & 2.35 & 1.58 & 1.91 \\
\hline
\end{tabular}

$T_{o}$ has been calculated out already. As shown in Table 3, the PI parameter identification results are varying as the calculated main opening time constant changes. In conclusion, the PI parameters identified depend on the calculation results of the main opening and closing time constant. The higher the calculated $T_{o}$ is, the higher the identified $K_{p}$ is.

Taking the three groups of parameters in Table 3 into simulation model, the valve opening results are shown in Figure 10.

In Figure 10, the parameters of simulated curve 1 are $K_{p}=$ 9.52, $K_{i}=10.72$. The parameters of simulated curve 2 are $K_{p}=6.83, K_{i}=7.7$, and the parameters of simulated curve 3 are $K_{p}=8, K_{i}=8.87$. With small disturbance 
TABLE 3: Identification results using GA-PSO algorithm.

\begin{tabular}{lcccc}
\hline Parameters & Range & $T_{o}=2.54 \mathrm{~s}$ & $T_{o}=1.89 \mathrm{~s}$ & \\
\hline$K_{p}$ & $0 \sim 100$ & 9.52 & 6.83 & $T_{o}=2.14 \mathrm{~s}$ \\
$K_{i}$ & $0 \sim 100$ & 10.73 & 7.7 & 8 \\
\hline
\end{tabular}
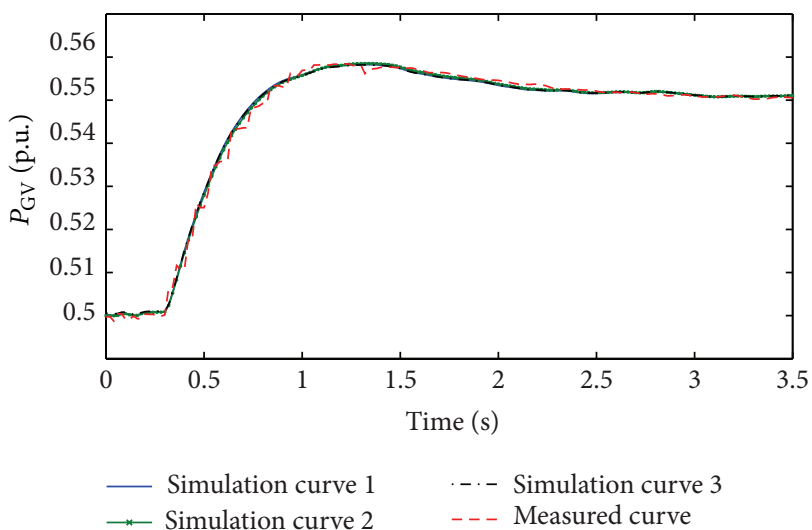

(a)

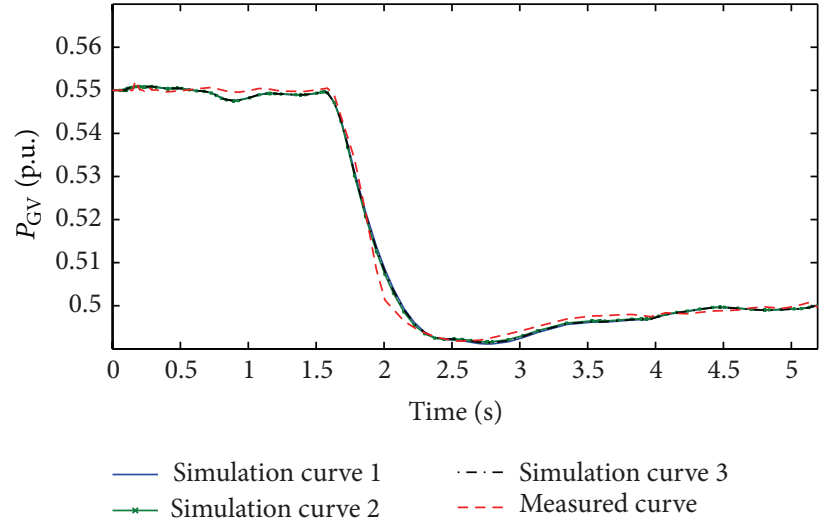

(b)

FIGURE 10: Valve opening simulation and measured contrast.

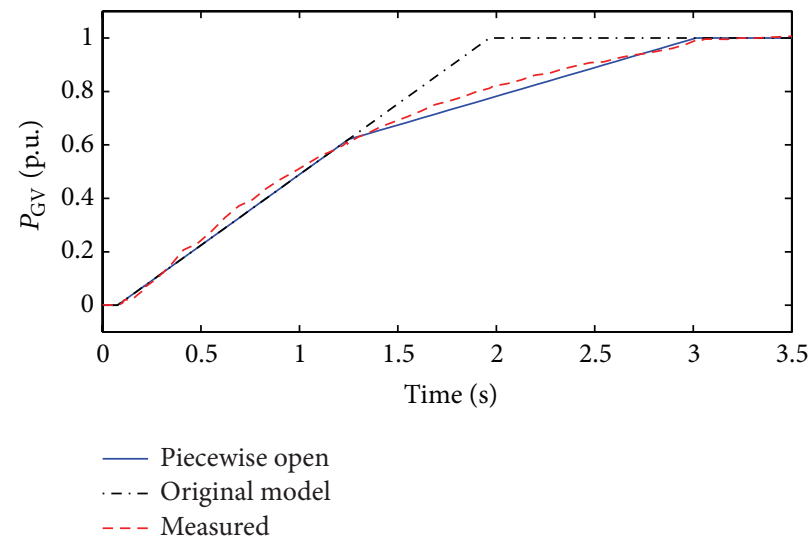

(a)

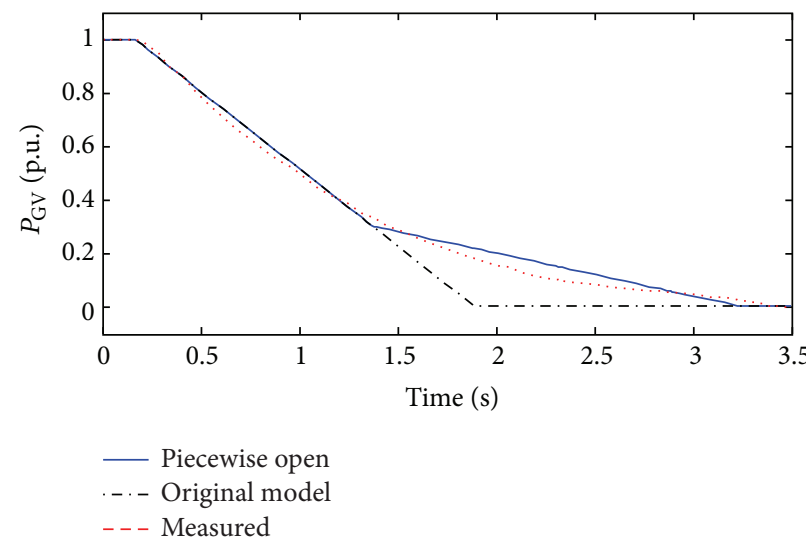

(b)

FIGURE 11: Valve fully open and close simulation comparison.

experimental tests contrast, the simulation results of three groups of parameters are consistent with the measured data.

\subsection{Actuator Comparison under Large Disturbance Test. As} shown in Figure 7, the measured fully open or close test curve is nonlinear, so a certain group of oil motive opening and closing time constants can not match with the measured curve. The main and auxiliary piecewise opening and closing time constants are adopted. The specific plan is as follows.

(a) When valve fully opens, the oil motive opening time switches from 1.89 seconds to 4 seconds at the valve opening of 0.64 .

(b) When valve fully closed, the oil motive closing time switches from 1.58 seconds to 5.7 seconds at the valve opening of 0.3 .
For instance, for Qujing power plant, the parameters are $T_{o}=1.89$ seconds, $T_{o 1}=4$ seconds, $T_{c}=1.58$ seconds, $T_{c 1}=5.7$ seconds, $Y_{o}=0.64$, and $Y_{c}=0.3$. Actuator PI parameters are $K_{p}=6.83, K_{i}=7.7$. The comparison of measured and simulation data with and without piecewise oil motive opening/closing time constants is shown in Figure 11.

The simulation results using the actuator piecewise linear model with main and auxiliary piecewise opening and closing time constants coincide with the measured curve (see Figure 11). In conclusion, when the valve is nonlinear, adopting main and auxiliary piecewise opening and closing time constants is not able to influence the simulation of valve under small disturbance. At the same time, simulation under large disturbance is more consistent with the measured curve. Thus, it can solve the problem of nonlinearity of the valve. But using fixed oil motive opening/closing time constants, 
the difference between the simulation and the measured curve under large disturbance is significant.

\section{Conclusion}

The GA-PSO parameter identification algorithm is studied and the effectiveness of GA-PSO algorithm is validated by multiple test functions and simulation results. Aimed at actuators in certain power plants whose valve fully open and fully close tests are nonlinear, three segmented curves (i.e., the whole segment curve, the front segment curve, and the middle segment curve) are selected to calculate the main opening and closing time constants and their effect on the PI parameter identification is studied. The conclusion is that the higher the calculated value of the main opening and closing time constant is, the higher the proportion link of actuator is.

Although the existing servo and actuator system model can meet the simulation need under small disturbance of the valve, it has large error with tests under large disturbance. The actuator piecewise linear model with main and auxiliary piecewise opening and closing time constants increases the feasibility of this model, which can fit the cases when the valve is nonlinear. The actual power plant cases verify the reliability of the established governor actuator piecewise linear model and its parameters are effective.

\section{Conflict of Interests}

The authors have declared that no conflict of interests exists.

\section{Acknowledgments}

This work is funded by the National Natural Science Foundation of China (51307123) and China Postdoctoral Science Foundation (2013M531736).

\section{References}

[1] J. L. Dineley and P. J. Fenwick, "The effects of prime-mover and excitation control on the stability of large steam turbine generators," IEEE Transactions on Power Apparatus and Systems, vol. 93, no. 5, pp. 1613-1623, 1974.

[2] L. Pereira, D. N. Kosterev, D. Davies, and S. Patterson, "New thermal governor model selection and validation in the WECC," IEEE Transactions on Power Systems, vol. 19, no. 1, pp. 517-523, 2004.

[3] L. Pereira, "New thermal governor model development: its impact on operation and planning studies on the Western Interconnection," IEEE Power and Energy Magazine, vol. 3, no. 3, pp. 62-70, 2005.

[4] W. Zhang, F. Xu, W. Hu, M. Li, W. Ge, and Z. Wang, "Research of coordination control system between nonlinear robust excitation control and governor power system stabilizer in multimachine power system," in Proceedings of the IEEE International Conference on Power System Technology (POWERCON '12), pp. 1-5, October-November 2012.

[5] L. Pereira, J. Undrill, D. Kosterev, D. Davies, and S. Patterson, "A new thermal governor modeling approach in the WECC," IEEE Transactions on Power Systems, vol. 18, no. 2, pp. 819-829, 2003.
[6] IEEE Committee, "Dynamic models for steam and hydro turbines in power system studies," IEEE Transactions on Power Apparatus and Systems, vol. 92, no. 6, pp. 1904-1914, 1973.

[7] V. Kola, A. Bose, and P. M. Anderson, "Power plant models for operator training simulators," IEEE Transactions on Power Systems, vol. 4, no. 2, pp. 559-565, 1989.

[8] W. Shinohara and D. E. Koditschek, "A simplified model based supercritical power plant controller," in Proceedings of the 35th IEEE Conference on Decision and Control, vol. 4, pp. 4486-4491, Kobe, Japan, December 1996.

[9] G. K. Stefopoulos, P. S. Georgilakis, N. D. Hatziargyriou, and A. P. S. Meliopoulos, "A genetic algorithm solution to the governorturbine dynamic model identification in multi-machine power systems," in Proceedings of the 44th IEEE Conference on Decision and Control, and the European Control Conference (CDC-ECC '05), pp. 1288-1294, December 2005.

[10] T. Inoue and H. Amano, "A thermal power plant model for dynamic simulation of load frequency control," in Proceedings of the IEEE PES Power Systems Conference and Exposition (PSCE '06), pp. 1442-1447, November 2006.

[11] B. Vahidi, M. R. B. Tavakoli, and W. Gawlik, "Determining parameters of turbine's model using heat balance data of steam power unit for educational purposes," IEEE Transactions on Power Systems, vol. 22, no. 4, pp. 1547-1553, 2007.

[12] S. Jiang, Q.-J. Chen, and W.-Y. Cai, "Simulation optimizing strategy for parameters of hydro-governor," Proceedings of the Chinese Society of Electrical Engineering, vol. 28, no. 3, pp. 102106, 2008.

[13] C. Jiang and P. Yan, "Neural network PID control system for the FTGS," in Proceedings of the 2nd International Conference on Intelligent Computation Technology and Automation (ICICTA '09), pp. 87-90, October 2009.

[14] D. J. G. Morrell and B. W. Hogg, "Identification and validation of turbo-generator models," Automatic, vol. 26, no. 1, pp. 135-156, 1990.

[15] C. Alippi and V. Piuri, "Identification of non-linear dynamic systems in power plants," in Proceedings of the 38th Midwest Symposium on Circuits and Systems, vol. 1, pp. 493-496, August 1995.

[16] S. Lu and B. W. Hogg, "Dynamic nonlinear modelling of power plant by physical principles and neural networks," International Journal of Electrical Power and Energy System, vol. 22, no. 1, pp. 67-78, 2000.

[17] A. N. Abdalla, K. Li, and S. J. Cheng, "Parameter identification of governor-turbine system based on a PSO algorithm," Dynamics of Continuous Discrete and Impulsive Systems-Series B-Applications \& Algorithms, vol. 14, no. 3, pp. 1-6, 2007.

[18] S. Chen, T. Mei, M. Z. Luo, and X. Q. Yang, "Identification of nonlinear system based on a new hybrid gradient-based PSO algorithm," in Proceedings of the International Conference on Information Acquisition (ICIA '07), pp. 265-268, Seogwipo-si, Republic of Korea, July 2007.

[19] I. Ghatuari, N. Mishra, and B. K. Sahu, "Performance analysis of automatic generation control of a two area interconnected thermal system with nonlinear governor using PSO and de algorithm," in Proceedings of the International Conference on Energy Efficient Technologies for Sustainability (ICEETS '13), pp. 1262-1266, Nagercoil, India, April 2013.

[20] M. Dulau and D. Bica, "Simulation of speed steam turbine control system," Procedia Technology, vol. 12, pp. 716-722, 2014. 
[21] M. Ažubalis, V. Ažubalis, A. Jonaitis, and R. Ponelis, "Identification of model parameters of steam turbine and governor," Oil Shale, vol. 26, no. 3, pp. 254-268, 2009.

[22] Working Group on Prime Mover and Energy Supply Models for System Dynamic Performance Studies, "Dynamic models for fossil fueled steam units in power system studies," IEEE Transactions on Power Systems, vol. 6, no. 2, pp. 753-761, 1991.

[23] J. J. Liang, A. K. Qin, P. N. Suganthan, and S. Baskar, "Comprehensive learning particle swarm optimizer for global optimization of multimodal functions," IEEE Transactions on Evolutionary Computation, vol. 10, no. 3, pp. 281-295, 2006.

[24] X. Xu and L. Lei, "The research of advances in adaptive genetic algorithm," in Proceedings of the IEEE International Conference on Signal Processing, Communications and Computing, pp. 1-6, Xian, China, September 2011. 


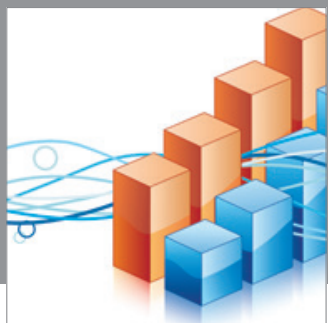

Advances in

Operations Research

mansans

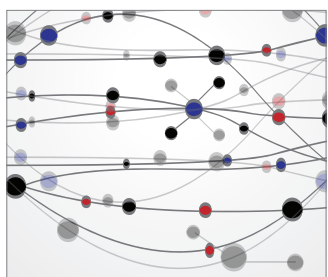

The Scientific World Journal
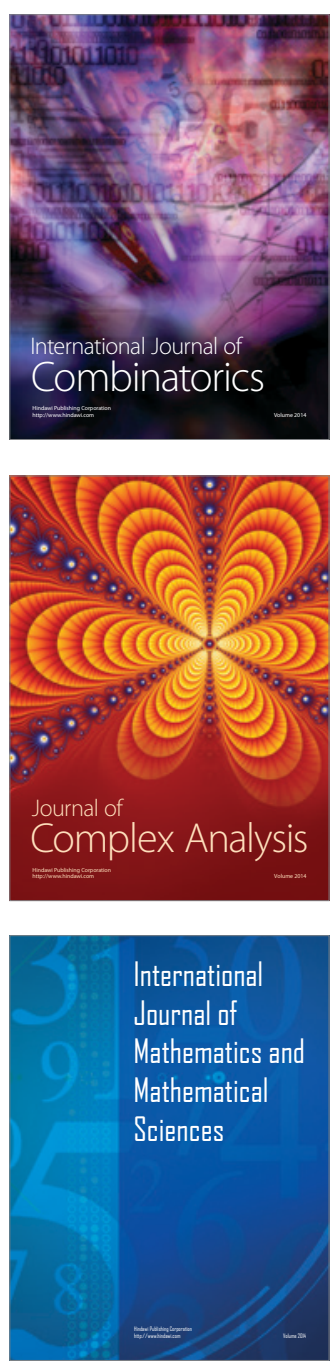
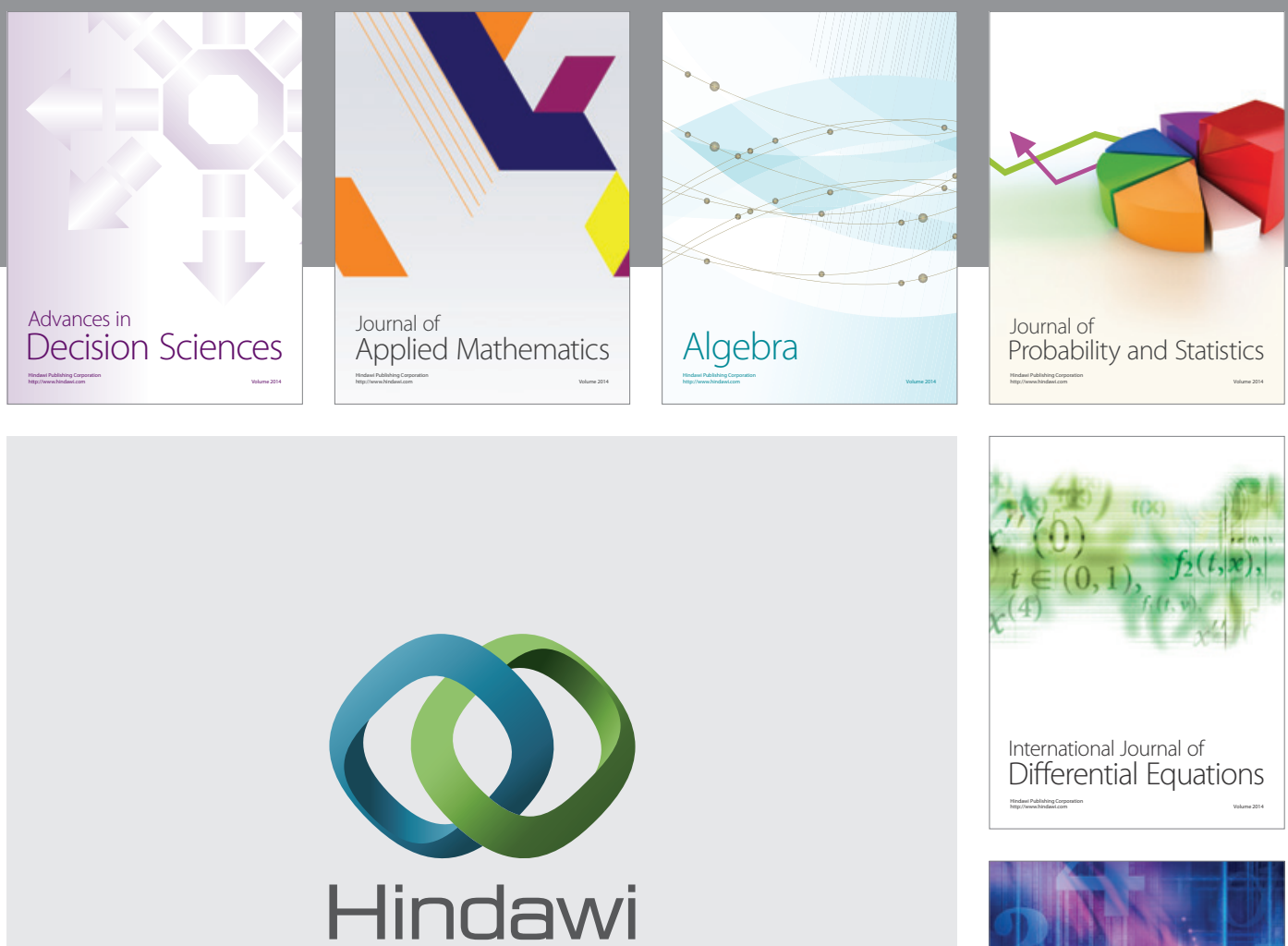

Submit your manuscripts at http://www.hindawi.com
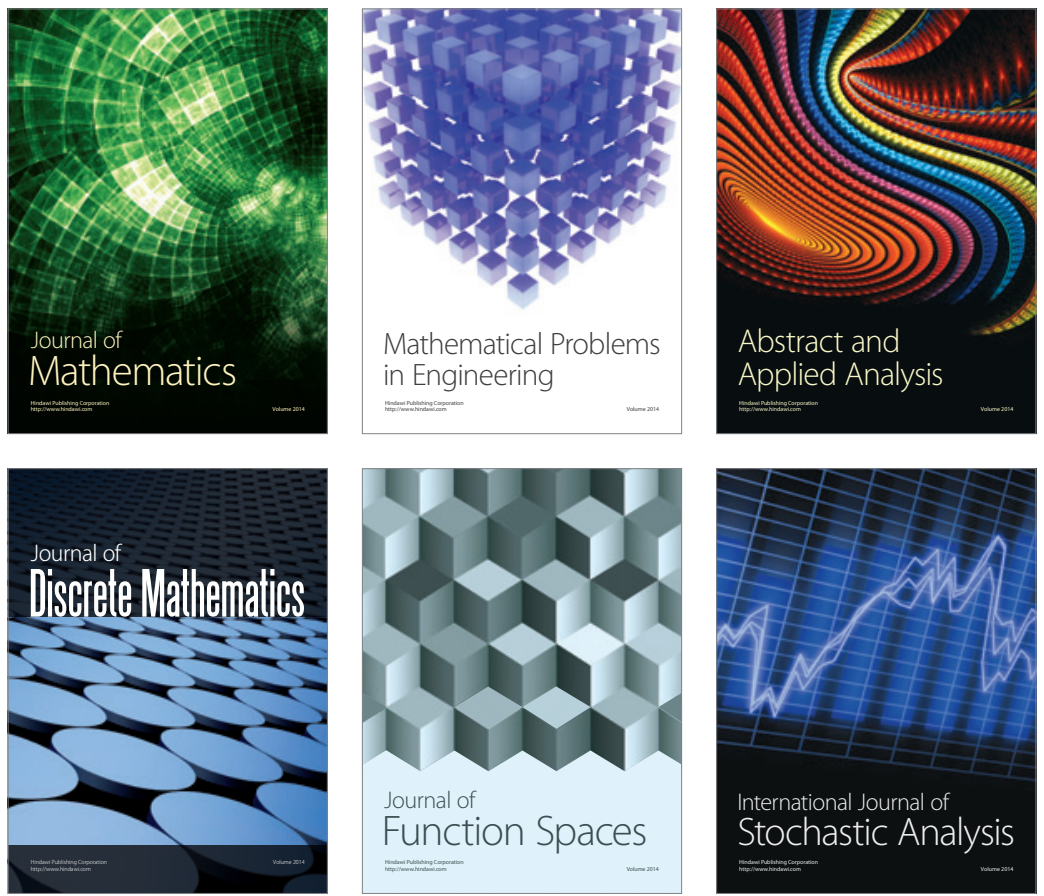

Journal of

Function Spaces

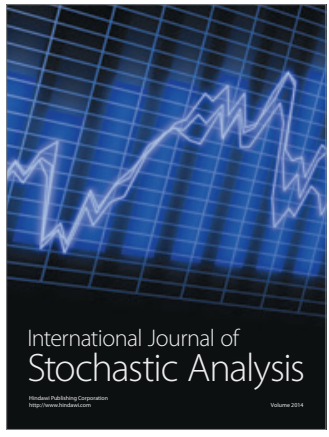

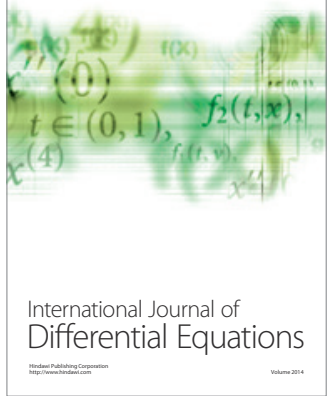
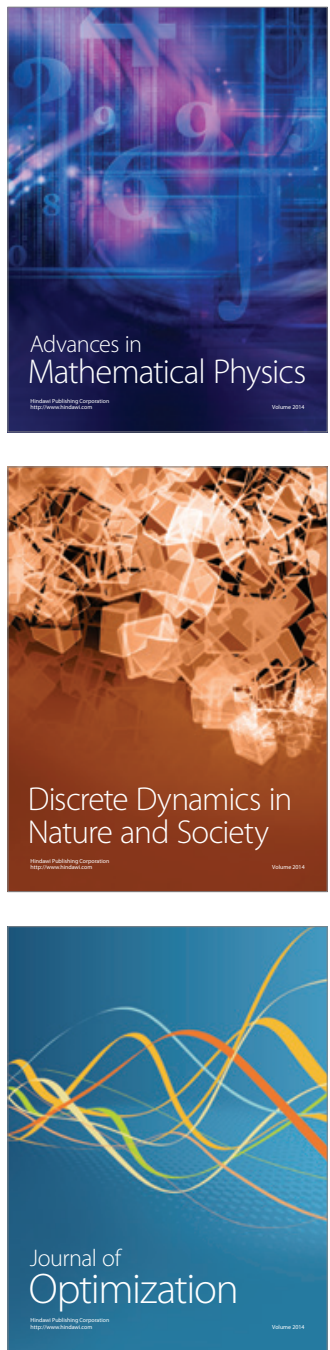